\title{
Low Grade Inflammation as a Common Pathogenetic Denominator in Age-Related Diseases: Novel Drug Targets for Anti-Ageing Strategies and Successful Ageing Achievement
}

\author{
G. Candore ${ }^{1}$, C. Caruso ${ }^{1, *}$, E. Jirillo ${ }^{2}$, T. Magrone ${ }^{3}$ and S. Vasto ${ }^{1}$
}

\author{
${ }^{l}$ Immunosenescence Unit, Department of Pathobiology and Biomedical Methodologies, University of Palermo; ${ }^{2}$ National Institute of \\ Gastroenterology, Castellana Grotte, Bari, Italy; ${ }^{3}$ Immunology, Faculty of Medicine, University of Bari, Bari, Italy
}

\begin{abstract}
Nowadays, people are living much longer than they used to do, however they are not free from ageing. Ageing, an inexorable intrinsic process that affects all cells, tissues, organs and individuals, is a post-maturational process that, due to a diminished homeostasis and increased organism frailty, causes a reduction of the response to environmental stimuli and, in general, is associated to an increased predisposition to illness and death. However, the high incidence of death due to infectious, cardiovascular and cancer diseases underlies a common feature in these pathologies that is represented by dysregulation of both instructive and innate immunity. Several studies show that a low-grade systemic inflammation characterizes ageing and that inflammatory markers are significant predictors of mortality in old humans. This pro-inflammatory status of the elderly underlies biological mechanisms responsible for physical function decline and agerelated diseases such as Alzheimer's disease and atherosclerosis are initiated or worsened by systemic inflammation. Understanding of the ageing process should have a prominent role in new strategies for extending the health old population. Accordingly, as extensively discussed in the review and in the accompanying related papers, investigating ageing pathophysiology, particularly disentangling agerelated low grade inflammation, is likely to provide important clues about how to develop drugs that can slow or delay ageing.
\end{abstract}

Keywords: Ageing, age-related diseases, diet, drug, inflammation, longevity.

\section{INTRODUCTION}

Nowadays, people are living much longer than they used to do, however they are not free from ageing. Ageing, an inexorable intrinsic process that affects all cells, tissues, organs and individuals, is a post-maturational process that, due to a diminished homeostasis and increased organism frailty, causes a reduction of the response to environmental stimuli and, in general, is associated to an increased predisposition to illness and death. Actually, it is characterized by a state of reduced ability to maintain health and general homeodynamics of the organism. Why we age is a question answered by evolutionary biologists in terms of allocation of resources, and by gerontologists in terms of damage and repair. However, the ageing phenotype is a complex inter-action of stochastic, environmental, genetic and epigenetic variables. These variables do not create the ageing phenotype but generate the lack of molecular fidelity and therefore as the random accumulation of damage in the human organism's cells, tissues, or whole organism during life increases, the probability of disease and death also augments in proportion [1-4].

In the Western countries, if we compare the mortality rate in people over 65 years, versus individuals ranging between 25 and 44 years, it increases to 100-fold for stroke, and chronic lung disease, 92-fold for heart disease, 89-fold for pneumonia and influenza and 43 -fold by cancer [1]. Common observation tells us that even the apparently healthy people differ in the length of healthy, or successful, ageing period. Some experience healthy state until their seventies or eighties, while some others, the centenarians, last than hundred years. Thus, one of the crucial questions posed by gerontologists is: why we do not age at the same rate and how could we predict the rate of ageing [5].

However, the high incidence of death due to infectious, cardiovascular and cancer diseases underlies a common feature in these pathologies that is represented by dysregulation of both instructive and innate immunity. Several studies show that a low-

Address correspondence to this author at the Immunosenescence Unit, Department of Pathobiology and Biomedical Methodologies, University of Palermo, Corso Tukory 211, 90134 Palermo, Italy; Tel: +390916555911; Fax: +390916555933; E-mail: marcoc@ @unipa.it grade systemic inflammation characterizes ageing and that inflammatory markers are significant predictors of mortality in old humans. This pro-inflammatory status of the elderly underlies biological mechanisms responsible for physical function decline and age-related diseases such as Alzheimer's disease (AD) and atherosclerosis which are initiated or worsened by systemic inflammation [5-7].

In the society, the public perception of advanced ageing involves the inability to survive due to chronic diseases and the combined loss of mobility, sensory functions, and cognition with an exponential growth of health costs linked to increased size of elderly in the Western World [8]. So, preventive therapeutic interventions to slow ageing are urgently needed.

\section{IMMUNOSENESCENCE}

In the elderly, the waning of the immune responsiveness in the elderly renders this population increasingly susceptible to infectious diseases, leading to resurgence of latent infections, and also to supra-infection by opportunistic organisms. In this age group, these infections contribute significantly to morbidity, and frequently lead to irreversible frailty and dependency. However, the individual contributing factors to immunosenescence are many and varied, due to the multi-factorial complexity of the immune system. It is often difficult to determine whether changes in a particular cell type are intrinsic to that cell, or caused by environmental changes, or both This is particularly the case for lymphocytes, where the interplay between $\mathrm{B}$ cells and $\mathrm{T}$ cells is crucial for effective responses, where if one subset is affected it will change the function of the other one [9-12].

Anecdotally, the clinical relevance of immunosenescence is well-documented, but exact detailed information is, in fact, hard to come by. Immunosenescence is a very vaguely-defined descriptive term covering the deleterious age-associated changes to immunity observed in all mammals studied so far. Early studies indicated that responses to mitogens predicted mortality to some degree, and since then many studies have probed associations between survival and parameters of both innate and acquired immunity. An emerging consensus suggests that maintenance of appropriate immunity is 
essential for exceptional longevity and, by implication, also for "normal" longevity [9-12].

Lifelong and chronic antigenic load results one of the driving force of immunosenescence, by reducing the number of virgin antigen non-experienced $\mathrm{T}$ cells, and filling the immunological space with expanded clones of memory and effector, antigen experienced $\mathrm{T}$ cells. These cells are also responsible, at least in part, for the pro-inflammatory status of elderly through the cytokine production. In parallel with such an increase, the production $\mathrm{T}$ cell compartment tends to decline with age of about two orders of magnitude, and could be considered the other leading force of immunosenescence. In fact, $\mathrm{T}$ repertoire is generated and maintained by the thymic production and output of new $\mathrm{T}$ lymphocytes, naïve for their antigen. Such thymic activity is extremely efficient during childhood, but has a very low activity in the elderly. Thus, the repertoire of cells available to respond to antigenic challenge from previously unencountered pathogens is shrinking $[9,13]$.

Some mechanisms by which the immune system is maintained during ageing are discussed, paying particular attention to the crosstalk between the central organ, the thymus, where $T$ cells come from, and the periphery, where $\mathrm{T}$ cells emigrate and exert their functions [14]. The different factors involved in the generation, maintenance and survival of the $\mathrm{T}$ cell pool hare considered. Several strategies aimed at improving thymic functionality are currently receiving a growing interest, and some of them are based on molecules that are produced by, and/or act on immune cells. Data on the possible use of these molecules, including cytokines like interleukin (IL)-7, IL-15 and keratinocyte growth factor, to restore thymic function are reviewed and discussed. The paper suggests that modulation of the functionality of the immune system by cytokines could also be useful to enhance cell-mediated immunity and to improve the responses to vaccines, but further studies are needed to achieve such an important goal [14].

Literature on immunosenescence has focused mainly on $\mathrm{T}$ cell impairment, but the B cell compartment is also affected in aged resulting in impaired quality of the antibody response. Until recently it was considered that the most likely cause of B cell failure was a lack of effective $\mathrm{T}$ cell help in a T-dependent reaction. However, there are T-independent functions of B cells, such as the polysaccharide responses that are crucial for anti-bacterial protection, which also appear to be lacking in later life. Changes in $\mathrm{B}$ cell number and repertoire have been described, and decreased $\operatorname{IgM}$ and $\operatorname{IgD}$ levels in the elderly suggest a shift from the naïve (CD27-) compartment of the B cell branch towards the memory (CD27+) compartment. However, these data are controversial since not all studies have shown this [10,15-17].

Recently, the $\operatorname{IgD}(-) \mathrm{CD} 27(-)$ double-negative $\mathrm{B}$ cell population, increased in the elderly, has been analysed, suggesting hat these expanded cells are late memory or exhausted cells that have downmodulated the expression of CD27 and filled the immunologic space in the elderly. These cells might be the age-related manifestation of time-enduring stimulation or dysregulation of the immune system [18].

To better characterize B cell immunosenescence, B cell compartment has been examined in two classes of individuals, old people and centenarian offspring [19]. In fact, it has been demonstrated that the centenarian offspring, who are typically in their 70s and 80s, have a survival advantage when compared with agematched controls whose parents died at an average life expectancy $[20,21]$. As expected, in both cohorts a decreased B cell count has been observe. However, in centenarian offspring, naïve B cells are more abundant whereas exhausted memory cells (DN B cells, IgDCD27-) do not show the increase previously demonstrated in healthy elderly donors. These data are similar to that found in previously experiments on young subjects. So, these preliminary results show that centenarian offspring do not have the typical trend of memory/naive B cell subsets observed in elderly people and this is in agreement with the higher levels of $\operatorname{IgM}$ in the serum of centenarian offspring in comparison with data obtained in agematched controls. This reservoir of naive B cell might be one of the causes that make centenarian offspring able to keep fighting off new infections, hence prolonging their life. So, B cell subset changes could represent a hallmark of successful or unsuccessful ageing and could be used as a biomarker [19].

In fact, to identify immunological biomarkers is an useful tool for antiageing strategies aimed to slow ageing and to postpone death by preventing infectious diseases [5].

\section{AGE-RELATED DISEASES \& THERAPEUTICS}

Most age-related diseases have complex aetiology and pathogenic mechanisms. A body of experimental and clinical evidence suggests that both innate and the clonotypic immune system are usually involved in the pathogenesis of these chronic diseases. However, inflammatory responses appear to be the prevalent triggering mechanism driving tissue damage associated with different age-related diseases and the term "Inflammaging" has been coined to explain the underlining inflammatory changes common to most age-associated diseases $[6,7]$.

The first line of immune defence mainly operates by detection of a broad range of molecular patterns foreign to mammalian tissues, called pathogen-associated molecular patterns that induce the activation of the innate immunity and inflammatory response. These germ cell-encoded proteins recognize microbial pathogens or ligands from damaged tissues based on shared molecular structures and induce host responses that localize the spread of infection and enhance systemic resistance to infection. Several cell types contribute to innate immunity and the mononuclear phagocyte lineage plays a pivotal role in innate immunity. Monocytes, macrophages and their tissue-differentiated derivatives, such as microglia in the nervous system, express pattern recognition receptors, namely various scavenger and Toll-like receptors (TLRs). TLR activation also induces the expression of a wide number of genes encoding proteins, such as cytokines, with regulatory functions upon leukocyte activation and tissue inflammation. Therefore, the capacity of each individual organism to regulate the activation of innate immunity and local inflammatory responses is crucial for initiating defensive action against pathogens, limiting tissue damage and enhancing fast recovery and tissue healing $[6,7,22]$.

In response to cell injury elicited by trauma or infection the inflammatory response sets in, constituting a complex network of molecular and cellular interactions directed to facilitate a return to physiological homeostasis and tissue repair. The response is composed of both local events and a systemic activation mediated by cytokines. If tissue health is not restored or in response to stable low grade irritation, inflammation becomes a chronic condition that continuously damages the surrounding tissues. In fact, during chronic inflammatory immune responses, tissue injury and healing proceed simultaneously. The collateral damage caused by this type of inflammation usually accumulates slowly, some-times asymptomatically for years but can eventually lead to severe tissue deterioration $[7,23]$.

Low grade inflammation has emerged as critical in the pathogenesis of several age-related chronic diseases as $\mathrm{AD}$, atherosclerosis, type 2 diabetes, sarcopenia, frailty and functional disability. These diseases appear to be correlated, leading to the concept of an age-related disease, which may be linked by the process of inflammation. So, genes involved in the regulatory pattern of inflammation should play a role in human ageing, furthermore high serological levels of pro-inflammatory mediators like cytokines and $\mathrm{C}$ reactive protein seem to be the marker of unsuccessful ageing $[6,7,24]$. 
However, a wide range of different aetiological factors is likely to contribute to increased low-grade inflammatory activity in elderly populations including the contribution of different tissues (adipose tissue, muscle), organs (brain, liver), immune system and ecosystems (gut microbiota) [25]. On the other hand, a recent hypothesis suggests that the reduction in lifetime exposure to infectious diseases and other sources of inflammation, the cohort mechanism, contributes to the historical decline in old-age mortality [26], pointing out long-life pathogen burden as the most important factor for age-related inflammation. Accordingly, some studies have linked an individual's exposure to past infection to levels of chronic inflammation and to increased risk of heart attack, stroke, and cancer $[6,7,26]$.

The oral cavity is involved in several physiologic activities, such as language, posture, mastication, swallowing, prosthetic retention. It has been established that the process of ageing includes a general progressive decline in the body's total skeletal musculature mass and its performance, which includes masticators and mimic facial muscles. Thus the aging process may lead to dramatic changes in the condition of teeth, oral mucosae, alveolar bone and salivary glands, even if age alone does not seem to play an exclusive role in these impairments. Dental, periodontal, oral mucosal, and salivary diseases have a detrimental and compounding affect on oral health in elderly persons, yet oral disease is not necessarily a concomitant of growing older. Similarly, numerous systemic diseases, drugs, and other medical treatments can adversely affect oral functions in older adults. These disorders must be recognized and managed appropriately by health care practitioners who will be able to contribute to eradicating disease, restoring function, and improving the quality of a person's life [27].

On the other hand, persistent peripheral multibacteria infection such as periodontitis (PD), associated with gram-negative anaerobic bacteria capable of exhibiting localized and systemic infections in the host, has been proposed as possible aggravating cofactor in subjects with vascular disease. In PD the balance between bacteria and host response is altered, resulting in a production of high levels of pro-inflammatory mediators and low levels of anti-inflammatory ones. Locally, these molecules act in concert to amplify the inflammatory reaction and activate the effector mechanisms responsible for tissue destruction. Moreover, inflammatory chemokines and cytokines are elevated in plasma of PD patients, thus, contributing to the systemic inflammatory burden and exerting potential systemic effects. Data regarding the PD association with neurodegenerative disorders are lacking; however, it seems plausible that, during $\mathrm{PD}$, cytokines increase in $\mathrm{AD}$ brain due to stimulation of trigeminal nerve fibres, or directly from bacterial products and/or bacteria. It seems relevant that in the NUN study a relationship between teeth loss and $\mathrm{AD}$ was found, but only in $\mathrm{APO} \varepsilon 4$ negative subjects [28-30].

Buccal epithelium is a relatively permeable, robust nonkeratinized tissue and blood vessels drain directly into the jugular vein; due to its particular features, it has been of increasing interest to researchers as an alternative site of drug administration. Recent studies have investigated the delivery of a variety of drugs through the buccal mucosa in order to assess both local and systemic, either positive or adverse, effects. In conclusion, buccal mucosa might be considered a promising site for effective, safe and non-invasive transmucosal sustained drug delivery [31]. According to this hypothesis, interesting results have been obtained in an experimental model on the in vivo trasbuccal delivery of galantamine, a drug used for in $\mathrm{AD}$ therapy. The in vivo animal trial has established the efficacy of an electronically-controlled device for the transbuccal drug delivery of galantamine. This could be a revolutionary approach to drug administration in $\mathrm{AD}$ even if further studies in vivo in human beings are required. Such an innovative approach could also be used for other types of medication that allows such non invasive transmucosal delivery although other experiments must be carried out for each candidate drug prior to deciding on the suitability of so called "IntelliDrug" approach [32].

Finally, osteoarthritis (OA) is a very common inflammatory disease in the elderly. According to the American College of Rheumatology, nearly 70 percent of people over age 70 have X-ray evidence of $\mathrm{OA}$, although only half ever develop symptoms. Notwithstanding, due to the huge amount of persons affected, OA is a frequent cause of disability [33]. The current therapeutic approaches with non-steroidal anti-inflammatory drugs (NSAIDs) or steroids do not delay the OA progression or reverse joint damage. Moreover, they may cause relevant systemic side effects. On the basis of the published trials, it is suggested that viscosupplementation therapy with hyaluronic acid physiologic component of the synovial fluid and is reduced in OA joints is a safe and effective method in the management of $\mathrm{OA}$ resistant to conventional therapies. The use of hyaluronic acid is mainly recommended when NSAIDs are contraindicated or badly tolerated, when NSAIDs or steroids are inefficacious or in young patients who are candidates for prothesis [34].

The process of life for the individual is the struggle to preserve its biological and immunological integrity, nonetheless organism integrity comes with a price of responsiveness to systemic inflammation which must be finely tuned, otherwise dysregulation becomes a damaging accompany [1,7]. Inflammation is not 'per se' a negative phenomenon: it is the response of the immune system to pathogenic viruses or bacteria. Thorough out evolution, man has been set to live about 40 or 50 years but in today's world the immune system is active for several decades compared with the past centuries. This long period of activation may lead to chronic inflammation which inexorably damages several/all organs and is the phenotype linked to both ageing and chronic disease [6,7].

How can centenarians survive with inflammageing? Even if centenarians have an increased level of inflammatory mediators in comparison to old subjects and they are very frail, inflammageing is compatible with longevity (100 years of age or more); this paradox may be explained because centenarians have also high level of antiinflammatory cytokines and the protective genotype of important molecules (such as those belonging to natural immunity) [24], (see also below). Therefore, the most proper approach to tackle and manage inflammageing is to follow a sort of "mirror-strategy": since inflammageing is a pleiotropic process where many different factors operate, in the same way pleiotropic interventions acting on different targets and at different levels at the same time are to be preferred and chosen, in a kind of mimic way [25].

\section{NEURODEGENERATION}

AD is a progressive neurodegenerative illness affecting elderly people. In fact, the prevalence of $\mathrm{AD}$ rises exponentially from $1 \%$ at age of 65 to approximately $40-50 \%$ by the age of 95 ; it also represents a growing public health problem as life expectancy increases [35]. Initial manifestations of AD include subtle memory loss and forget-fulness, which progress to profound memory loss, cognitive dysfunction and behavioural and emotional disturbances that may eventually interfere with the patient's ability to perform basic activities of daily living. The pathological hallmarks are neurofibrillary tangles and senile plaques. The former are mainly composed by a cytoskeletal protein named tau, which becomes hyperphosphorylated and self aggregates into neurofibrillary tangles. Senile plaques are characterized by the accumulation of proteins in the form of $\beta$-pleated sheet fibrils, which are composed mainly of a 42 amino acids peptide known as $\beta$-amyloid (A $\beta$ ) [36] In particular, the "amyloid cascade hypothesis" supports the idea that $\mathrm{A} \beta$ is the main pathogenetic factor of $\mathrm{AD}$ because the aberrant metabolism of the amyloid precursor protein and the subsequent massive production and deposition of the peptide in extracellular sites are responsible for a concatenate series of events that have as a final result neurotoxicity and consequent neuronal death $[37,38]$. 
In addition to its well-known neurotoxic role, recent evidences suggest $A \beta$ putative implication in regulating normal brain homeostasis, in which, under normal conditions, $A \beta$ may also play a key role in the regulation of synaptic activities and brain functions [39]. Actually, experimental evidence indicates that $A \beta$ peptides are constitutively produced by brain cells and are found in the nM-pM range in the cerebrospinal fluid of non-demented individuals and in media from neuronal cell cultures, suggesting that, as well as having a potential pathological role in $\mathrm{AD}, \mathrm{A} \beta$ peptides under normal conditions may have a role in the regulation of brain functions, consistent with their ubiquitous presence and normal synthesis. During normal ageing these neuromodulatory roles may be affected probably due to changes in the peptide burden, since $A \beta$ levels have reported to increase in this stage of life. Hence, it should be useful to explore whether the increased presence of this peptide in healthy aged subjects may predict a potential conversion to neurodegeneration, mainly towards AD. Nonetheless, the putative neuromodulatory role of $A \beta$ in the context of ageing is nowadays unknown. For these reasons, studies about $A \beta$ spectrum of action (brain areas and neurotransmitter systems affected) might suggest new therapeutic targets in order to sustain those functions which may be altered during ageing [39].

AD prevention is an important goal of ongoing research. Two objectives must be accomplished to make prevention feasible: 1) individuals at high risk of $\mathrm{AD}$ need to be identified before the earliest symptoms become evident, by which time extensive neurodegeneration has already occurred and intervention to prevent the disease is likely to be less successful and 2) safe and effective interventions need to be developed that either reduce or slow the accumulation of AD neuropathology or lead to a decrease in clinical expression of this pathology $[38,40]$.

Events contributing to $\mathrm{AD}$ development are numerous and complex. The pathogenesis involves a multitude of variables many of which remain to be quantified. Recent work highlighting the importance of neuroinflammation in $\mathrm{AD}$, has led to the prospect of exciting future therapeutic options. A better understanding of the interplay between cytokines, their receptor activity, second messengers, lipid metabolism and protein modification is necessary. Although there are many events which can lead to neuroinflammation, this process represents a common pathway of disease development [41].

Several inflammatory factors influencing AD development, i.e. environmental factors (pro-inflammatory phenotype) and/or genetic factors (pro-inflammatory genotype) have been described $[36,40,42]$. A growing number of studies in AD have also reported alterations in systemic immune responses including changes in lymphocyte distribution and activation. Studies in animal models support the notion that immune cells infiltrate the brain and may modulate the disease [43]. Moreover, variations in immuneinflammatory genes such as cytokine, cyclooxygenase (COX), lipooxygenease (LO), TLR have also been considered to be important in the risk for $\mathrm{AD}[36,40]$. In particular, cytokine gene polymorphisms have been claimed to play a key role in pathophysiology of $\mathrm{AD}$, as demonstrated by two recent meta-analysis performed on IL-1 $\beta$ and tumor necrosis factor(TNF)- $\alpha[44,45]$. However, data on a meta-analysis focused on IL-6, a pleiotropic cytokine involved in the regulation of the acute inflammatory response, do not seemingly support a role in AD pathophysiology [46]. However, it is to take into account that inflammatory mediators do not act alone but they act in a complex network reciprocally interacting [47]. Moreover, inflammation is strictly related to reactive oxygen species (ROS) production. Mammalian cells have developed highly regulated inducible defensive systems, whose cytoprotective functions are essential in terms of cell survival. When appropriately activated, each one of these systems has the possibility to restore cellular homeostasis and rebalance redox equilibrium. Activation of antioxidant pathways is particularly important for tissue with relatively weak endogenous antioxidant defenses, such as the brain. Increasing evidence, in fact, support the idea that reduction of cellular expression and activity of antioxidant proteins and consequent augment of oxidative stress play a central role in ageing processes and neurodegenerative diseases, including $\mathrm{AD}[5,42]$. Regarding molecules with anti-oxidant properties, a number of experimental and epidemiological studies have recently supported the beneficial effects of some commonly used natural products in preventing various pathologic conditions ranging from cardiovascular diseases to cancer. Spices and herbs often contain phenolic substances with potent anti-oxidative and chemopreventive properties. Among others, curcumin seems to have a possible role in AD $[38,46]$, playing several mechanisms. However, it is able to clear amyloid via the induction of heat shock proteins (HSPs), that function as molecular chaperones to block protein aggregate formation. Recently curcumin has been evaluate in a pilot clinical trial in AD patients, with preliminary encouraging results [38]. So, further in vitro and in vivo studies using curcumin-like molecules will give important information on the feasibility of developing new pharmacological strategies [46].

As above discussed, AD patients show impaired memory and cognitive functions. Although several neurochemical deficits have been described, explanation of the nature of the cognitive disturbance is focused on the "cholinergic hypothesis". The AD symptoms are the direct consequence of a severe deficit in the cholinergic neurotransmission following a progressive degeneration in forebrain and, in particular, in the nucleus basalis magnocellularis (NBM) [48,49]. The degeneration of cell bodies in NBM causes the loss of neuronal cortex projections accompanied by a reduction of the brain levels of the neurotransmitter acetylcholine (ACh) and the biosynthetic enzymes choline acetyl transferase and acetylcholinesterase [50,51]. Many different strategies have been investigated to improve cholinergic neurotransmission, including the reduction of synaptic ACh hydrolysis by Cholinesterases inhibition and the increase of ACh synthesis. In an integrated study to develop simple choline esters as cholinergic agents potentially useful against AD. Simple derivatives, such as the choline esters, have been shown to exert pharmacological effects in vivo models restoring the cortical activity similar to that obtained with anticholinergic agents, such as tacrine or donepezil, currently used in the anti AD palliative therapy [52].

In regard to the molecular and cellular mechanisms that determine whether brain ageing occurs successfully or manifests dysfunction or disease, the major classes of signalling molecules important in brain ageing include neurotrophic factors (NFTs), neurotransmitters, cytokines and steroids. In particular, an important role in balancing protective/neurodegenerative processes is played by NFTs, which are central to many aspects of nervous system function since they regulate the development, maintenance and survival of neurons and neuron-supporting cells such as glia and oligodendrocytes. A vast amount of evidence indicates that alterations in levels of NFTs or their receptors can lead to neuronal death and contribute to ageing as well as to the pathogenesis of neurodegenerative diseases such as AD. On the other hand, data of recent human clinical studies and trials are available unraveling NFT therapeutic potential in a variety of diseases states and ageing. In particular, nerve growth factor, brain-derived neurotrophic factor, glial-cell-line-derived neurotrophic factor, insulin-like growth factor I and ciliary neurotrophic factor have been examined. NTFs have been shown to promote the survival of specific populations of brain neurons under experimental conditions relevant to brain aging and neurodegenerative disorders. NTFs exert their effects on the development and function of neurons by binding to cell surface receptors possessing intrinsic tyrosine kinase activity, in turn activating down-stream kinases including the phosphatidylinositol-3-kinase, protein kinase $\mathrm{C} \gamma$, and the mitogenactivated protein kinase, as well as several small G-proteins 
$[53,54]$. As a consequence, some transcription factors are activated and ultimately the expression of genes that encode proteins involved in regulating neuronal survival, differentiation and plasticity is induced. Cellular and molecular mechanisms by which neurotrophic factors may influence cell survival and excitability are also critically examined to provide novel concepts and targets for the treatment of physiological changes bearing detrimental functional alterations and of different diseases affecting the central nervous system during ageing [53].

The role of the so-called cognitive kinases and the importance of their age-related alterations has been examined [55]. In fact, considering the critical implication of protein kinases in converting the extracellular signals into biological responses, it is logic to hypothesize that their functional alterations may directly contribute to age-dependent neuronal dysfunctions thus reverberating on memory processes. Within this context, numerous studies point out on several kinases as positive regulators for memory function and suggest that various memory disturbances are the result of a deficit in kinase signalling pathways. Many kinases associated with synaptic function are indeed age-sensitive; in fact, various studies in aged animals indicate that a reduction in kinases expression/ function in some brain areas correlates with ageing and memory decline. Within the large family of kinases involved in signal transduction, which have been studied in relation to ageing, memory and cognition, Protein Kinase C, Protein Kinase A, Calcium/calmodulin-dependent Protein Kinase, Tyrosine Kinase, are widely accepted as key actors in signalling pathways associated with memory. In line with these concepts, pharmacological modulation of kinases may lead to neuroprotective effects that can prevent or counteract age-related memory impairment [55].

However, taking into account the future epidemics of $\mathrm{AD}$ [35,36], studies on pathophysiology of AD opening the way for new diagnostic approaches for early diagnosis hence preventive treatment are welcome.

\section{CANCER AND AGEING}

In most mammalian species carefully examined, cancer incidence goes up with roughly exponential kinetics, starting at about the average of the lifespan [56]. So, cancer is generally recognized as an age-related disease; the median age for cancer diagnosis in industrialized countries is nearly 70 years of age and is expected to increase [57]. This might be due to a common biology that links cancer and ageing or cancer might merely represent a coincidental correlate of ageing, i.e. due to an increased duration of carcinogenesis [56,58]. However, incidence and mortality rates of most human cancers consistently increase up to age 90 , but they plateau and decline thereafter, suggesting that centenarians are protected from developing cancer. Accordingly, cancer deaths account for $40 \%$ from age 50 to 70 and less than $4 \%$ for centenarian people [59]. Actually, centenarians, their offspring and siblings have better chances to escape major age related disease including cancer [60]; autoptic studies clearly show that, in centenarians, the cause of death by cancer and metastatic spread are lower than expected [61].

An increase in somatic mutations has been documented in aged cells, and presumably relates to cumulative lifetime exposure to endogenous and exogenous DNA damaging agents, as well as to an accumulation of mutations during DNA replication $[59,62]$. However, as previously stated, in oldest old individuals cancer prevalence does not increase, but declines, despite the longer exposure to exogenous and endogenous factors causing cancer.

As previously stated, a low-grade systemic inflammation characterizes ageing and this pro-inflammatory status underlies biological mechanisms responsible for age-related inflammatory diseases, including cancer $[59,62]$. Another mechanism responsible might be the reduced immune function, i.e., immunosenescence in the elderly [63]. The importance of the immune system in preventing tumor formation, immunosurveillance, is supported by epidemiological evidence [64]

Clinical and epidemiologic studies have suggested a strong association between chronic infection, inflammation, and cancer; it is known that alcohol abuse can lead to liver and pancreatic cancer, smoking to airway inflammation and lung carcinoma, and infectious disease such as hepatitis $\mathrm{C}$ virus or papilloma infections to liver and cervical cancer [59,62]. In addition, many other inflammatory triggers are associated with other malignancies, including microbial infection, such as Helicobacter pylori infection, associated with gastric cancer, autoimmune responses associated with inflammatory bowel disease and colorectal cancer and sexualtransmitted infections with prostatitis and prostate cancer [65-67].

Inflammation seems to play a role in carcinogenesis by causing cellular and genomic damage, promoting cellular turnover, and creating a tissue microenvironment that can enhance cell replication, angiogenesis and tissue repair. Actually, tumors are thought to develop from chronic inflammation, where uncontrolled cell proliferation occurs in a milieu rich in pro-inflammatory cytokines, inflammatory mediators, and growth factors normally involved in chronic and unresolved inflammation. In normal tissues, antiinflammatory cytokines are synchronically upregulated after the pro-inflammatory cytokines are produced, leading to inflammation resolution. In chronic inflammation, this does not occur, resulting in a continuous production of ROS, leading to oxidative DNA damage and reduced DNA repair, and increased proliferation $[59,62,68,69]$.

In this framework, an interesting model is represented by prostate cancer (Pca), which is featured by a complex pathophysiology with a strong genetic component. Multiple genes seem to influence Pca risk and several single nucleotide polymorphisms (SNPs) of candidate genes modifying Pca susceptibility have been identified. It is noteworthy the potential association of common SNPs in pro-inflammatory genes with Pca risk, since chronic inflammation is assumed to play a key role also in prostate carcinogenesis. With the aim to identify candidate genes in order to develop new strategies for both prevention and treatment of Pca, it has been investigate the potential role of common SNPs of a gene cluster, TLR-4, TLR-2, COX-2 and 5-Lo, involved in innate and inflammatory response, has been investigated in Pca cases, agematched controls and centenarians from Sicily [70]. Statistical analysis evidenced a significant association of some pro-inflammatory gene SNPs with an increased risk of Pca. In particular, the use of centenarians as "super-controls" [62] enhanced the possibility of identifying the genetic profile characterizing susceptibility and/or resistance to Pca.

On the other hand, it is well established that an increase of n-6 polyunsaturated (i.e. arachidonic and arachidonic-converted linoleic acids) fat dietary intake enhances carcinogenesis and promotes tumorigenesis through oxidative metabolism. By contrast, n-3 polynsaturated fatty acids (i.e. fish oil) have antitumorigenic effects [71-75]. It is generally known that COX and LO enzyme classes mediate the oxidative metabolism of $n-6$ polyunsaturated fatty acids and generate a cascade of biological active inflammatory molecules also implicated in tumor development are overexpressed during carcinogenesis [59,62]. NSAIDs modulating arachidonic acid metabolism have been utilized in cancer chemoprevention $[59,62]$. The gastrolesivity of a prolonged use of nonselective NSAIDs, due to the COX inhibition, an important housekeeping gene of the gastrointestinal system, contraindicated their use in chemoprevention. Moreover, cardiovascular side effects emerged in the long-term use of COX-2 specific inhibitors rising doubts on their use for cancer chemoprevention [76-78]. In light of these recent observations, the development of novel cancer chemoprevention strategies is necessary and LO-inhibitors could be of interest. However, data obtained with tumor cell lines indicate that multiple drug combination of distinct $\mathrm{COX}-2$ and 5-LO inhibitors at clinically feasible concentrations were more effective than each 
agent alone. Larger clinical trials are necessary to confirm the clinical effectiveness and safety of COX/LO dual inhibitors and to define the possibilities of widespread use, especially in "frail" patients, in which age-related pluripathologies were present [79].

As previously stated, viral infections and alcohol play a relevant role in the pathophysiology of hepatocellular carcinoma (HCC) [59] that is the most frequent primary neoplasm of the liver, and is the fourth most common malignancy worldwide. It is also the third leading cause of cancer-related deaths. However, between $15 \%$ and $50 \%$ of HCC develops in the absence of a known etiology of liver disease, and different lines of evidence identify in non-alcoholic fatty liver disease (NAFLD) a possible relevant risk factor for occurrence of HCC. Insulin resistance, steatosis, oxidative stress and imbalances in adipokine/cytokine interplay, the most important factors involved in NAFLD pathogenesis and progression, could also have a determinant role in liver carcinogenesis by promoting cellular growth and DNA damage. Recently, behavioral therapy and various insulin sensitizing agents have been tested in the treatment of NAFLD. A number of studies suggest that these approaches improve insulin resistance and reduce steatosis, necroinflammation and fibrosis. A potential role of these therapeutic strategies in the prevention of hepatocarcinogenesis can thus be envisaged [80].

Finally, polyploidization, a state of increased number of chromosomes, is recognized as a part of a developmental program. Nonetheless, polyploidization also accompanies ageing [81,82]. It is believed that tetraploid cells precede aneuploid ones in the early phases of tumor development. Division of tetraploid cells is restricted by the active tetraploid checkpoint. Tetraploid cells that are able to overcome this checkpoint give rise to increased genomic instability and tumor progression [83]. Recently, a cellular senescence program activated by oncogene expression was shown to act as a natural barrier against cancer development. Senescent cells were detected in many benign, but not malignant, human and animal tumors [84,85]. Senescence can actually block cell transformation provided this check-point is active. Cancer cells that escaped the checkpoint block are still able to undergo senescence upon anticancer treatment. Induction of cancer cell senescence is often correlated with high ploidy formation. Some polyploid cells can escape senescence and give progeny with numerical changes of chromosomes. Divisions of polyploid cancer cells on the road to senescence can be responsible for the ineffectiveness of anticancer therapy. Altogether, this implies polyploidy as a link between cellular senescence, cancer development and possible cancer renewal after treatment [86].

In time, the better knowledge of the function and the regulation of inflammatory pathway in cancer as well as our increasing understanding of the molecular mechanisms involved in cancer development, including cancer stem cell behavior and regulation of cellular senescence pathways, are essential to progress in the design of new drugs more specially directed on chemoprevention or chemotherapy of human cancers. This strategies could give important information for developing better molecular-targeted drugs, with minimal side effects, which together with healthier choices of nutrition and lifestyles, will help in reducing cancer incidence.

\section{CARDIOVASCULAR RISK}

For most of human history, famine and infection have been the primary causes of death. Hence, large portions of the human genome are devoted to genes involved in cellular metabolism in times of crisis (protection from starvation) and in immuneinflammatory responses (eradication of injury). These interrelated pressures might be expected to select for individuals with mild to moderate insulin resistance as well as with relatively enhanced inflammatory function. The adaptive pattern of an earlier time has resulted in a maladaptive response in our modern environment dominated by increasingly sedentary habits, an abundance of highcarbohydrate foods, and a reduced risk of mortality due to common infections. Accordingly, cardiovascular disease is the leading cause of death and illness in developed countries. The major contributor to cardiovascular disease is atherosclerosis, a progressive, multifactorial process that focally affects large arteries and is characterized by the accumulation of lipids and fibrous elements in their walls. Inflammation is demonstrated to play a crucial role in all the phases of the atherosclerotic process, from the initial steps of leukocyte recruitment to the eventual rupture of a vulnerable plaque. Risk factors for atherosclerosis and adult-onset diabetes closely overlap and the fact that the two disorders may derive from similar antecedents has lead to a "common soil" hypothesis, which suggests, in part, that both of these disorders share a mutual inflammatory and perhaps genetic basis. For our hunter/gatherer ancestors with a life expectancy of less than 40 years, the advantages of a moderate insulin resistance and a high cytokine responder overcame the possible inconveniences of atherosclerosis. In our current environment, these inconveniences may prove to be at the root of our ongoing epidemic of age-related inflammatory diseases [87-92].

Accordingly, several studies have analyzed the association between inflammatory gene polymorphisms and atherosclerosis and myocardial infarction (MI) [93-95]. In a case-control study on MI, SNPs in several inflammatory genes, such as IL-1 $\beta$, IL-6, IL-10, $\alpha-$ 1 -antichymotrypsin, TNF- $\alpha$ and interferon(IFN)- $\gamma$ genes along with SNPs of genes regulating vascular functions (vascular endothelial growth factor; VEGF) and cholesterol synthesis (hydroxymethylglutaryl CoA reductase; HMGCR) were investigated. Patients were genotyped and data were analyzed with a new mathematical algorithm named Auto Contractive Map (AutoCM). AutoCM was applied in MI patients with the aim to detect and evaluate the relationships among genetic factors, clinical variables and classical risk factors. In the connectivity map generated by AutoCM, a group of variables was directly linked with the MI status; these were: gender (male), early age at onset (50-65 years), HMGCR gene (CC wild type genotype), IL-1 $1 \beta C T$, IL-6 GG and VEGF CC genotypes. This direct link suggested a possible pathogenetic association with MI. These analyses suggested that genotypes of few inflammatory genes, a SNP in HMGCR gene, middle age, gender, low HDL and diabetes were very informative variables to predict the risk of MI [96].

Cardiovascular diseases are a late consequence of an evolutionary pro-inflammatory response programmed to resist infections in earlier life. Thus, genetic backgrounds promoting proinflammatory responses may play opposite roles in cardiovascular diseases and in longevity. Genetic polymorphisms responsible for a low inflammatory response might result in an increased chance of longer life span in an environment with a reduced pathogen burden, such as a modern-day health environment, which also permits obtaining a lower-grade survivable atherogenic inflammatory response [93]. In fact, centenarians are reservoirs of genetic and environmental information to successful ageing and local centenarian groups may help us to understand some of these secrets.

In Belfast it is present a centenarian cohort that survived the 1970 s epidemic of death from coronary heart disease in Northern Ireland, where cardiovascular mortality was almost highest in the world. These centenarians provided an opportunity to assess biological and genetic factors important in cardiovascular risk and ageing. Thirty-five ( 27 female, 8 male) centenarians, participants of the Belfast Elderly Longitudinal Free-living Ageing Study, were community-living and of good cognition at enrolment. Centenarians showed median body mass index at 25.7, systolic blood pressure $140 \mathrm{mmHg}$ and diastolic blood pressure $90 \mathrm{mmHg}$ respectively, and fasting glucose of $5.54 \mathrm{mmol} / \mathrm{l}$ with no sex-related difference. Lipoproteins showed median cholesterol 5.3, HDL 1.10 and LDL $3.47 \mathrm{umol} / \mathrm{l}$ respectively. Centenarian smokers showed no different blood pressure or lipid measurements compared with non-smokers. Malondialdehyde, a measure of lipid peroxidation, was low at 1.19 , 
and measures of antioxidant status showed variable results. Male centenarians did not carry any of the vascular risk genotypes studied APOE, Angiotensin-Converting Enzyme and Methylenetetrafolatedehydrogenase reductase, though this was not true for female centenarians. This small local study shows, apart from age, that Belfast centenarians carry a reasonably optimized risk profile with respect to cardiovascular disease. There is also some evidence suggesting that vascular risk factors and genotypes may be tolerated differently between the male and female centenarians. Maintaining an optimized cardiovascular risk profile seems likely to improve the chance of becoming a centenarian, especially for males $[93,97]$.

Ageing is a very complex process highly dependent on the interaction between individuals' genes and the environmental factors. Smoking, can be considered an accelerator of ageing, capable of affecting molecules, cells and organs of the whole human body. This means that smoke compromises not only life expectancy, but also the quality of the life, favouring the occurrence of non-autonomy. Non-smokers have a much higher life expectancy than smokers, and the suspension of smoking is accompanied, even in the elderly, by an increase in the survival time due to the reduction of smoke-induced biological damage [98]. A lot of epidemiologic study support the role of smoke in acute coronary syndrome (ACS) and MI. Obesity conferred an elevated risk of ACS in both healthy and less healthy subgroups of lifestyle behaviors: however, the authors found that obese individuals had a considerable lower risk if they were non-smokers [99-101]. Nonsmokers have a much higher life expectancy than smokers, and the suspension of smoking is accompanied, even in the elderly, by an increase in the survival time due to the reduction of smoke-induced biological damage. Today numerous quitting strategies exist, either of pharmacological or non-pharmacological type, which are also advantageous for the elderly person [98].

As previously stated, TLRs are principal mediators of rapid microbial recognition and function mainly by detection of pathogen-associated molecular patterns that do not exist in the host. Recognition of their ligands leads to a series of signaling events resulting in acute host responses, involved in killing pathogens. Until now, 13 mammalian TLR members have been identified. Each TLR appears to recognize distinct pathogen-associated molecular patterns, derived from various microorganisms, including bacteria, viruses, protozoa and fungi. Recognition of their ligands leads to a series of signaling events resulting in acute host responses, involved in killing pathogens. One of the best understood TLR members is TLR-4, involved in recognition of the lipopolysaccharide (LPS) [22].

A couple of papers have analysed the effects of LPS on embryonal cardiomyocites wich may constitute a valid experimental model in order to study LPS-induced inflammatory responses [102,103]. Results emerging from these studies suggest the existence of two signalling pathways induced by LPS treatment: an inflammatory response sustained by NF- $\kappa \mathrm{B}$ leading to TNF- $\alpha$ and NO release, and an anti-inflammatory response due to COX-2 activation. So, both NF-кB and COX-2 act as two key molecules able to determine the cell fate. The balance between pro and antiinflammatory responses ultimately may protect cardiomyocytes from an excessive cell loss deriving by endotoxin stress. Further characterization of these pathways could provide a wealth of information about the responses of cardiac cells to endotoxin stress, in order to identify pharmacological targets for heart protection during sepsis. At the same time, the immunocompromised host and, in particular, aged people are exposed to bacterial toxic products more than healthy population, and, therefore, detrimental effects on the heart should be taken into serious consideration by clinicians [102].

Furthermore, LPS-induced inflammatory response by cardiomyocytes is useful not only to identify the signalling pathways evoked by endotoxin receptor, including TLR-4, but also to suggest therapeutic targets for the control of myocardial dysfunction induced by infectious agents. In this respect, in elderly a continuous leakage of LPS from gut flora and/or external environment should be regarded as a possible cause of cardiac failure and, therefore, adequately prevented or treated [103].

Finally, a study on a cohort of Italian Caucasians comprising 490 type 2 diabetic and 349 control subjects investigated whether the $-1087 \mathrm{G} / \mathrm{A} \quad(\mathrm{rs} 1800896),-824 \mathrm{C} / \mathrm{T} \quad(\mathrm{rs} 1800871),-597 \mathrm{C} / \mathrm{A}$ (rs1800872) IL10 polymorphisms were associated with type 2 diabetes [104]. Stratifying the data according to IL-10 genotypes, trends for the progressive increase of glucose and neutrophil levels were observed in $-1087 \mathrm{GG}$ vs. $-1087 \mathrm{GA}$ vs. $-1087 \mathrm{AA}$ positive diabetic patients $(-1087 \mathrm{GG}<-1087 \mathrm{GA}<-1087 \mathrm{AA})$. In addition, evaluating the laboratory parameters according to the -597/-824/1087 derived haplotypes a significant increase of neutrophils was found in diabetic vs. non-diabetic -597A/ -824T/-1087A positive subject. In an attempt to integrate clinical laboratory and immunogenetic data to determine whether these factors taken together define sufficient risk sets for type 2 diabetes we performed the grade-of-membership analysis (GoM). GoM allowed to identify a population of subjects negative for IL-10 $-824 \mathrm{~T}$ allele, $74.4 \%$ of which were diabetic patients characterized by vascular damages, reduction of haematocrit, increase of blood urea nitrogen, creatinin and monocyte levels. These data seem to suggest that $-597 \mathrm{~A} /-$ $824 \mathrm{~T} /-1087 \mathrm{~A}$ negative subjects are more prone to the major type 2 diabetic vascular damages and allow to hypothesis that the contemporary evaluation of some simple hemato-chemical parameters and IL-10 SNPs may allow identifying diabetic patients with the worse prognostic profile, needing both better complication prevention planning and therapeutic strategies [104].

Some of the studies here outlined allow building a risk profile that potentially enables the early identification of individuals susceptible to disease and the possible design or use of drug at the right dose for a desired effect, that is, a pharmacogenomic approach for a given disease $[40,94]$.

\section{LONGEVITY}

The majority of above described immune-inflammatory aspects, that characterize ageing, are also detectable in extreme longevity, where a higher frequency of genetic markers associated with a reduced pro-inflammatory ability seems to counteract the onset of the main age-related inflammatory disorders. The data on the determinants of human longevity indicate that centenarians are a good choice for the study of longevity, because they represent an extreme phenotype, i.e., the survival tail of the population who escaped neonatal mortality, pre-antibiotic era illnesses, and fatal outcomes of age-related complex diseases. Centenarians are quite capable of mounting effective inflammatory responses; however, inflammatory status, correlated to increasing risk of developing frailty and diseases, is compensated by the concomitant development of strong and effective anti-inflammatory responses [24,25,105]; (see also above). Hence, the study of centenarians allows us to correlate longevity and some of the major age-related pathologies. Centenarians are remarkably enriched in "good" genotypes and show opposite frequencies of "bad" genotypes in comparison with patients affected by major age-related pathologies, such as cardiovascular disease, AD and cancer. So, they can be considered as "super-controls", allowing a reliable and accurate identification of the variants related to the major killer and as a further proof that longevity is, at least in part, the positive counterpart of unsuccessful ageing [24,59,61,62, 93,97,105-108].

A study on a group of nonagenarians has been performed in order to follow-up their survival [109]. The involvement of Hsp70 in cellular maintenance and repair mechanisms, including its role as an anti-inflammatory protein, makes it a suitable candidate for studying such associations [110-112]. Three single nucleotide polymorphisms, HSPA1A $(-110 \mathrm{~A}>\mathrm{C})$, HSPA1B $(1267 \mathrm{~A}>\mathrm{G})$, and 
HSPA1L (2437T $>$ C), present in the three HSP70 genes, were studied in a cohort of individuals born in the year 1905. This population cohort is a part of the longitudinal study of Danish nonagenarians. Since DNA samples were already collected in 1998, this gave them the opportunity to perform survival analysis on these subjects. Haplotype relative risk, and genotype relative risk were calculated to measure the effects of haplotypes and genotypes on human survival in a sex-specific manner. A significant association of HSPA1A-AA and HSPA1B-AA genotypes with poor survival was observed in female subjects. Also the female carriers of haplotype G-C-T had longer survival than the non-carriers. On an average, female carriers of the G-C-T haplotype live about one year longer than non-carriers. These results from the association of genotypes/haplotypes of HSP70 genes on human survival reiterate the view that the genes involved in stress response (and inflammation) are involved in the genetics of longevity [109].

Human ageing and longevity are complex and multi-factorial traits that result from a combination of environ-mental, genetic, epigenetic and stochastic factors, each contributing to the overall phenotype. The multi-factorial process of ageing acts at different levels of complexity, from molecule to cell, from organ to organ systems and finally to organism, giving rise to the dynamic "ageing mosaic". At present, an increasing amount of experimental data on genetics, genomics, proteomics and other -omics are avail-able thanks to new high-throughput technologies but a comprehensive model for the study of human ageing and longevity is still lacking $[3,61,107,113-116]$. Hence, system biology has been suggested to be a powerful tool to integrate and quantify high dimensionality but still fragmented data that are produced by increasing highthroughput technologies in the field of genomics, proteomics, metabolomics and other -omics [117]. It is proposed that a comprehensive analysis of this information is possible only through a systems biology approach, in a recursive process of "wet" and "dry" experiments. Actually, the existing information and new data generated by ad hoc experiments are put together in a comprehensive data set, which is then analyzed and used to generate predictive mathematical models. These new models can suggest new experiments, which in turn produce an enlarged data set and the analytic process restarts. This innovative approach can be performed only if specific expertise of analysis and computational power will be available, joint to more collaboration across disciplines and countries. This integrated approach will let us understand the ageing process at organism level and to identify targets for antiageing interventions [117].

However, data on centenarians discussed in the present paper suggest that "healthy ageing" is a real possibility for human beings and cast some doubt on the pessimistic view that extreme age must always be accompanied with severe diseases and/or disabilities.

\section{DIET AND AGEING}

In the elderly, nutrition monitoring in the elderly, and food consumption have the potential for dropping the rate of chronic diseases and improving quality of life by providing specific information to aid in the development of targeted dietary and other intervention strategies. In fact, many, if not all, age-related diseases are, partly preventable by diet and exercise, understanding the feasibility of good nutrition and the need to achieve and maintain a healthy weight [118]. Nowadays, it is known how minerals, vitamins, microelement deficiency can strongly influence the onset and the path of many chronic inflammatory degenerative disease. Eating well means ageing fine and delay, if not avoid, disease like diabetes type II, hypertension, obesity, cardiovascular disease and also, at least in part, osteoporosis and cancer. Therefore, it is important to identify dietary patterns and supplements, in addition to specific dietary components, in order to offer shelter against many chronic inflammatory disease. Furthermore, ageing is associated with frailty and malnutrition which direct consequences are leading to increased risk of many geriatric syndromes such as falls, delirium, functional decline and depressed immunity [119]. Recent studies found that frailty clinical phenotype is associated with pathologic laboratory markers suggesting a possible pathogenesis involving hormonal dysregulation, immunosenescence, procoagulation and pro-inflammatory status [120]. All the above pathways might be regulated and influenced by nutritional intervention upon administration of micronutrients, food supplementation and functional food.

"Let food be the medicine and medicine be the food" was embraced $\sim 2500$ years ago by Hippocrates and this tenet has acquired more audience in the last years with an ageing, healthconscious population, several changes in food regulations, technological advances and a marketplace ripe for the introduction of health-promoting products, know as "functional foods and food supplementation."

As an example, substance like berries have been recognized since the 1920s for their efficacy in treating urinary tract infections. More recent research has confirmed that condensed tannins (proanthocyanidins) in berries are the biologically active component and prevent $E$. coli from adhering to the epithelial cells lining the urinary tract. Moreover, additional beneficial effects of berries include enhancement of neuronal communication via increases in neuronal signaling and decreases in stress signals induced by oxidative/inflammatory stressors (e.g., NF- $\kappa \mathrm{B}$ ). Moreover, blueberry or concord grape juice supplementation in humans with mild cognitive impairment increased verbal memory performance. Taken together, these results suggest that a greater intake of highantioxidant foods such as berries, concord grapes, and walnuts may increase "health span" and enhance cognitive and motor function in ageing [121].

Food supplementation are essential elements needed by life in different quantities. They include microminerals, fatty acid, fiber and vitamins. Microminerals or trace elements include at least iron, cobalt, chromium, copper, iodine, manganese, selenium, zinc, and molybdenum. Many of these element have different capacities ranging from anti-oxidative stress to immunity regulation to chronic inflammatory disease regulation [122]. Functional foods are foods characterized for their added physiologic benefits, which may reduce chronic disease risk or otherwise optimize health. They represent the whole bench of substances covering potentially healthful products including any modified food or ingredient that may provide a benefit beyond the traditional nutrients. They comprise food like cereals, milk and breads and beverages which are fortified with vitamins and herbs. Among these we have also vitamins, herbal extracts, amino acids, polyamine, minerals and probiotics [122]. They are sold on the market as foods for general consumption (or "health foods") to be used as "supplements" to nutrition (diet).

Among others, one of the most known functional food is a class of biologically active components, that has received increasing attention in recent years, called probiotics and defined as "viable microorganisms that are beneficial to human health" $[9,123]$. They are, usually, microorganism already living in the intestine district such as Bifidobcteria, Enterococci and Lactobacilli. Several scientific works support the utilize of these functional ingredients for various health concerns including cancer, intestinal tract function, immune function, allergy, stomach health, urogenital health, cholesterol lowering and hypertension [9,124-126].

Substance like polyamines that seem to be affected by probiotics like Lactobacilli are quite interesting in this area because associated with cancer risk. These substances play an essential role in cell proliferation because cells produce their own internally, and they gather circulating polyamines that come from dietary sources, such as intestinal bacteria, and those excreted by other cells. Cells depend on polyamines for growth and their depletion represents a 
strategy for the treatment of cancer. In vitro Lactobacilli have shown to affect polyamine content on gastric cancer cells and in vivo significantly decrease the polyamine biosynthesis in preneoplastic condition [125-127].

Another substance that seems playing an important role in cancer is Curcumin, which is a phytochemical derived from rhizome of Curcuma Longa present in the spice turmeric that gives Indian curry its yellow colour. Curcumin seems to have effect as anti-inflammatory, anti-oxidant and against cancer. In this respect it looks influencing transcription factors, cyclin E and D and several growth factors. It is also a potent inducer of cell death including apoptosis, mitotic catastrophes and autophagy [128].

As discussed, inflammation is the hallmark of many age-related pathologies. Life style and nutrition can influence progress and dimming of the inflammatory status as for example controlling obesity, known as an inflammatory process mediated by soluble products released by both immune cells and adipocytes. Leptin, adiponectin and visfatin are the major adipocytokines in addition to classical cytokines such as TNF- $\alpha$, IL-1, IL-6, produced by adipocytes $[129,130]$. It is important as various food supplementation and functional food can have a role in switching-of the inflammatory pathway [130]. Lipoic acid is an essential cofactor for mitochondrial respiratory enzyme and has been shown to have potent anti-obesity properties in animals. It seems that its role is to guide a cross-talk between adipose tissue and skeletal muscle, mediating by the reduction of TNF- $\alpha$ and IL-6 production [131].

The benefit of the Mediterranean diet has been seen in healthy preobese/obese patients, since, as it is known, adipose tissue closely correlated with type II diabetes and coronary heart disease due to a low grade systemic inflammation. In fact a diet rich in fruit, vegetables, legumes, whole grains, fish, and low-fat dairy products are associated with lower incidence of various chronic diseases, as atherosclerosis, cardiovascular diseases, and cancer [132].

Inulin belongs to the class of carbohydrates know as fructans and it has been studied in the contest of lipid lowering effect and therefore having a great influence on cardiovascular disease. Inulinenriched pasta rises an increased interest because able modifying some of the metabolic risk factors for dysmetabolic diseases. Importantly, data in this issue suggest that inulin may positively modify glucose homeostasis, as demonstrated by the significant effects on fasting glucose levels, fructosamine, and HbA1c [133].

Donkey milk has been seen as an enhancer of acute phase response and to a lesser extent, of proinflammatory cytokine response while goat milk is rather a down regulator of acute inflammation, thus preventing massive infiltration of neutrophils into the senescent lung and, consequentially further damage to vital organs. Goat's milk seems to trigger gut macrophages to release NO which in turn seems to have cardioprotective, antiatherogenic and antibacterial effect contributing to longevity and at the same time regulate inflammatory cytokines and stimulate $\mathrm{IgA}$ at mucosal level. Moreover both donkey and goat milk seems to posses the capacity to modulate immunity through the stimulation of IFN- $\gamma$, lysozime, mucin, oligosaccarides, fatty acid, hormones and growth factors [134,135].

Also minerals like magnesium seems to have an important role in inflammation. Hypomagnesemia has been associated with inflammation and increased production of ROS. Poor magnesium status may trigger the development of a proinflammatory state both by causing excessive production and release of IL- $1 \beta$ and TNF- $\alpha$, and by elevating circulating concentrations of proinflammatory neuropeptides that trigger activation of low-grade chronic inflammation [136]. So a supplementation of magnesium seems to be of a help in human health. Sarcopenia, a typical ageing event, is strictly associated with loss of function, disability, malnutrition and hospitalization. Several studied have shown that magnesium depletion strongly impaired muscle performance [136]. As discussed, immunity plays a paramount role in ageing and inflammatory chronic disease therefore being able to trigger or influence innate or acquired immunity by micronutrient administration can be a tool to use close to generic medicine [2,9]. Once again magnesium, seems involved in immune component production like in immunoglobulin synthesis, C3 convertase, immune cell adherence, antibody dependent cytolysis, IgM lymphocyte binding and T helper $\beta$ cell adherence [136].

Long-term oxidative stress is believed to be one of the major factors contributing to ageing. The oxidative stress results from the shift toward ROS production in the equilibrium between ROS generation and the antioxidant defence. Oxygen free radicals as well as reactive nitrogen species (RNS), are products of normal cellular metabolism playing a dual role as both deleterious and beneficial species, since they can be either harmful or beneficial to living systems. The advantageous effects of ROS take place at low or moderate concentrations and imply their physiological roles in cellular responses to noxa, defence against infectious agents, cellular signaling and induction of a mitogenic response. The damaging effect occurs in biological systems when there is an overproduction of ROS/RNS on one side and a deficiency of enzymatic and non-enzymatic anti-oxidants on the other side. The harmful effect of redox regulation implicated diseases including cancer, diabetes mellitus, ischemia/reperfusion injury, inflammatory diseases, neurodegenerative disorders and ageing [137-140].

There are several compound described in literature recognized as antioxidant like vitamins and flavonoids. Among others it comes clear from literature that magnesium, in sufficient amount, prevents oxygen radicals formation by scavenging free radicals and inhibiting xanthine oxidase and nicotinamide adenine dinucleotide phosphate oxidase. In animal model low magnesium intake is associated with superoxide dismutase, hepatic glutathione and vitamin $\mathrm{E}$ decrease and increase of lipid peroxidation and malondialdehyde. Lipoic acid $\alpha$ has the ability to scavenge ROS and influence the tissue concentration of lipoate. Alpha-lipoic acid have other antioxidant properties including chelation of transition metals and the regeneration of other antioxidants such as glutathione, vitamin C and vitamin $\mathrm{E}[131,136,141]$.

Although there is evidence that certain functional foods or food ingredients can play a role in disease prevention and health promotion, safety considerations should be paramount. Safety concerns have recently been raised, particularly with regard to the seemingly indiscriminate addition of botanicals to foods. A plethora of "functional" bars, beverages, cereals and soups are being enhanced with botanicals, some of which may pose a risk to certain consumers. The safety issues related to herbs are complex and the issue of herb-drug interaction has received increasing attention

\section{CONCLUSION}

Nowadays, many countries have rising ageing populations and are facing an increased prevalence of age-related diseases and increasing healthcare costs. During the 20th century, life expectancy at birth rose by a remarkable 30 years in developed countries, initially because of reductions in infant, child, and maternal mortality and then because of declining mortality in middle and old age. In 1900, about $40 \%$ of babies born in countries for which reliable data existed were expected to live beyond age 65 . Today in these same countries more than $88 \%$ of all newborns will live past age 65 and at least $44 \%$ will live beyond age 85 [142-144]. However, the rapid rise in older people is accompanied by an increase in the number of people with chronic age-related diseases previously discussed. Elderly are less resistant to both environmental and pathological injury; in addition, they are less resistant to infection. Hence, the time has come to get more serious about the effort to slow human ageing or, on the other hand, to age successfully. In fact, success in increasing longevity in laboratory organisms has shown that ageing is not an immutable process [145,146]. It has 
been calculated that if ageing is slowed for seven years, the age specific risk of death, frailty, and disability will be reduced by about half at every age. People who reach the age of 60 in the future would resemble current 53 year olds, and so on. On the other hand, if ageing is combined with extended years of healthy life, it could also produce unprecedented social, economic, and health dividends [146,147].

Understanding of the ageing process should be a crucial component of such innovations and must have a prominent role in new strategies for extending the health of a population that is highly susceptible to the diseases of ageing [146]. Accordingly, as extensively discussed in the review and in the accompanying related papers, investigating ageing pathophysiology, particularly disentangling low grade inflammation, is likely to provide important clues about how to develop drugs that can slow or delay ageing [148].

\begin{tabular}{|c|c|c|}
\hline \multicolumn{3}{|c|}{ ABBREVIATIONS } \\
\hline $\mathrm{A} \beta$ & $=$ & $\beta$-amyloid \\
\hline Ach & $=$ & Acetylcholine \\
\hline ACS & $=$ & Acute Coronary Syndrome \\
\hline $\mathrm{AD}$ & $=$ & Alzheimer's disease \\
\hline AutoCM & $=$ & Auto Contractive Map \\
\hline $\mathrm{COX}$ & $=$ & Cyclo-oxygenase \\
\hline GoM & $=$ & Grade-of-membership analysis \\
\hline Hsp70 & $=$ & Heat shock protein 70 \\
\hline $\mathrm{HCC}$ & $=$ & Hepatocellular Carcinoma \\
\hline HMGCR & $=$ & Hydroxy-Methyl-Glutaryl CoA Reductase \\
\hline IFN & $=$ & Interferon \\
\hline IL & $=$ & Interleukin \\
\hline LO & $=$ & Lipo-oxygenease \\
\hline LPS & $=$ & Lipopolysaccharide \\
\hline MI & $=$ & Myocardial Infarction \\
\hline NFTs & $=$ & Neurotrophic Factors \\
\hline NSAIDs & $=$ & Mon-Steroidal Anti-Inflammatory Drugs \\
\hline NBM & $=$ & Nucleus Basalis Magnocellularis \\
\hline OA & $=$ & Osteoarthritis \\
\hline PD & $=$ & Periodontitis \\
\hline Pca & $=$ & Prostate cancer \\
\hline RNS & $=$ & Reactive Nitrogen Species \\
\hline ROS & $=$ & Reactive Oxygen Species \\
\hline SNPs & $=$ & Single Nucleotide Polymorphisms \\
\hline TLRs & $=$ & Toll-like Receptors \\
\hline TNF & $=$ & Tumor Necrosis Factor \\
\hline VEGF & $=$ & Vascular Endothelial Growth Factor \\
\hline
\end{tabular}

\section{REFERENCES}

[1] Troen BR. The biology of aging. Mt Sinai J Med 2003; 70: 3-22.

[2] Candore G, Colonna-Romano G, Balistreri CR, Di Carlo D, Grimaldi MP, Listi F, et al. Biology of longevity: role of the innate immune system. Rejuvenation Res 2006; 9: 143-8.

[3] Candore G, Balistreri CR, Listì F, Grimaldi MP, Vasto S, ColonnaRomano G, et al. Immunogenetics, gender, and longevity. Ann N Y Acad Sci 2006; 1089: 516-37.

[4] Rattan SI. Hormesis in aging. Ageing Res Rev 2008; 7: 63-78.

[5] Vasto S, Scapagnini G, Bulati M, Candore G, Castiglia L, ColonnaRomano G, et al. Biomarkers of ageing. Front Biosci 2010; S2: 392-402.

[6] Vasto S, Candore G, Balistreri CR, Caruso M, Colonna-Romano G, Grimaldi MP, et al. Inflammatory networks in ageing, age-related diseases and longevity. Mech Ageing Dev 2007; 128: 83-91.
[7] Licastro F, Candore G, Lio D, Porcellini E, Colonna-Romano G, Franceschi C, et al. Innate immunity and inflammation in ageing: a key for understanding age-related diseases. Immun Ageing 2005; 2 : 8.

[8] Balducci L. Aging, frailty, and chemotherapy. Cancer Control 2007; 14: 7-12.

[9] Candore G, Balistreri CR, Colonna-Romano G, Grimaldi MP, Lio $\mathrm{D}$, Listi' $\mathrm{F}$, et al. Immunosenescence and antiimmunosenescence therapies: the case of probiotics. Rejuvenation Res 2008; 11: 42532.

[10] Caruso C, Buffa S, Candore G, Colonna-Romano G, Dunn-Walters $\mathrm{D}$, Kipling $\mathrm{D}$, et al. Mechanisms of immunosenescence. Immun Ageing 2009; 6:10.

[11] Larbi A, Franceschi C, Mazzatti D, Solana R, Wikby A, Pawelec G. Aging of the immune system as a prognostic factor for human longevity. Physiology (Bethesda) 2008; 23: 64-74.

[12] Vasto S, Caruso C. Immunity \& Ageing: a new journal looking at ageing from an immunological point of view. Immun Ageing 2004; 29: 1 .

[13] De Martinis M, Franceschi C, Monti D, Ginaldi L. Inflamm-ageing and lifelong antigenic load as major determinants of ageing rate and longevity. FEBS Lett 2005; 579: 2035-9.

[14] Pinti M, Nasi M, Lugli E, Gibellini L, Bertoncelli L, Roat E, et al. $\mathrm{T}$ cell homeostasis in centenarians: from the thymus to the periphery. Curr Pharm Des 2010; 16: 597-603.

[15] Colonna-Romano G, Aquino A, Bulati M, Di Lorenzo G, Listì F, Vitello S, et al. Memory B cell subpopulations in the aged. Rejuvenation Res 2006; 9: 149-52.

[16] Colonna-Romano G, Bulati M, Aquino A, Scialabba G, Candore G, Lio D, et al. B cells in the aged: CD27, CD5, and CD40 expression. Mech Ageing Dev 2003, 124: 389-93.

[17] Colonna-Romano G, Bulati M, Aquino A, Vitello S, Lio D, Candore G, et al. B cell immunosenescence in the elderly and in centenarians. Rejuvenation Res 2008, 11: 433-9.

[18] Colonna-Romano G, Bulati M, Aquino A, Pellicanò M, Vitello S, Lio $\mathrm{D}$, et al. A double-negative (IgD-CD27-) B cell population is increased in the peripheral blood of elderly people. Mech Ageing Dev 2009; 130: 681-90.

[19] Colonna-Romano G, Buffa S, Bulati M, Candore G, Caruso C, Lio $\mathrm{D}$, et al. B cells compartment in centenarian offspring and old people. Curr Pharm Des 2010; 16: 604-608.

[20] Terry DF, Wilcox M, McCormick MA, Lawler E, Perls TT. Cardiovascular advantages among the offspring of centenarians. J Gerontol A Biol Sci Med Sci 2003; 58: M425-31.

[21] Terry DF, Wilcox MA, McCormick MA, Perls TT. Cardiovascular disease delay in centenarian offspring. J Gerontol A Biol Sci Med Sci 2004; 59: 385-9.

[22] Balistreri CR, Colonna-Romano G, Lio D, Candore G, Caruso C. TLR4 polymorphisms and ageing: implications for the pathophysiology of age-related diseases. J Clin Immunol 2009; 29: 406-15.

[23] Mitchell RN, Cotran RS. Acute and chronic inflammation. in robbins basic pathology. Saunderrs, Philadelphia: USA 2003.

[24] Capri M, Salvioli S, Monti D, Caruso C, Candore G, Vasto S, et al. Human longevity within an evolutionary perspective: the peculiar paradigm of a post-reproductive genetics. Exp Gerontol 2008; 43: 53-60.

[25] Cevenini E, Caruso C, Candore G, Capri M, Nuzzo D, Duro G, et al. Age-related inflammation: the contribution of different organs, tissues and systems. How to face it for therapeutic approaches. Current Pharm Des 2009; 15: 609-618.

[26] Finch CE, Crimmins EM. Inflammatory exposure and historical changes in human life-spans. Science 2004; 305: 1736-9.

[27] Guiglia R, Musciotto A, Compilato D, Procaccini M, Lo Russo L, Ciavarella $\mathrm{D}$, et al. Aging and oral health: effects in hard and soft tissues. Curr Pharm Des 2010, 16: 619-630.

[28] Hingorani AD, D'Aiuto F. Chronic inflammation, periodontitis and cardiovascular diseases. Oral Dis 2008; 14: 102-4.

[29] Kamer AR, Dasanayake AP, Craig RG, Glodzik-Sobanska L, Bry M, de Leon MJ. Alzheimer's disease and peripheral infections: the possible contribution from periodontal infections, model and hypothesis. J Alzheimers Dis 2008; 13: 437-49.

[30] Stein PS, Desrosiers M, Donegan SJ, Yepes JF, Kryscio RJ. Tooth loss, dementia and neuropathology in the Nun study. J Am Dent Assoc 2007; 138: 1314-22. 
[31] Campisi G, Paderni C, Saccone R, Di Fede O, Wolff A, Giannola LI. Human buccal mucosa as an innovative site of drug delivery. Curr Pharm Des 2010; 16: 641-652.

[32] Giannola LI, Paderni C, De Caro V, Florena AM, Wolff A, Campisi G. New prospectives in the delivery of Galantamine for elderly patients using the IntelliDrug intraoral device: in vivo animal studies. Curr Pharm Des 2010; 16: 653-659.

[33] Lawrence RC, Helmick CG, Arnett FC, Deyo RA, Felson DT, Giannini EH, et al. Estimates of the prevalence of arthritis and selected musculoskeletal disorders in the United States. Arthritis Rheum 1998; 41: 778-99.

[34] Abate M, Pulcini D, Di Iorio A, Schiavone C. Viscosupplementation with intra-articular hyaluronic acid for treatment of osteoarthritis in the elderly. Curr Pharm Des 2010; 16: 631-640.

[35] Wang XP, Ding HL. Alzheimer's disease: epidemiology, genetics, and beyond. Neurosci Bull 2008; 24: 105-9.

[36] Vasto S, Candore G, Listì F, Balistreri CR, Colonna-Romano G, Malavolta M, et al. Inflammation, genes and zinc in Alzheimer's disease. Brain Res Rev 2008, 58: 96-105.

[37] Gasparini L, Racchi M, Binetti G, Trabucchi M, Solerte SB, Alkon $\mathrm{D}$, et al. Peripheral markers in testing pathophysiological hypotheses and diagnosing Alzheimer's disease. FASEB J 1998; 12: 17-34.

[38] Racchi M, Uberti D, Govoni S, Memo M, Lanni C, Vasto S, et al. Alzheimer's disease: new diagnostic and therapeutic tools. Immun Ageing 2008; 5: 7.

[39] Mura E, Lanni C, Preda S, Pistoia F, Sarà M, Racchi M, et al. Betaamyloid: a disease target or a synaptyc regulator affecting agerelated neurotransmitter changes? Curr Pharm Des 2010; 16: 672683.

[40] Vasto S, Candore G, Duro G, Lio D, Grimaldi MP, Caruso C. Alzheimer's disease and genetics of inflammation: a pharmacogenomic vision. Pharmacogenomics 2007; 8: 1735-45.

[41] McNaull BB, Todd S, McGuinness B, Passmore AP. Inflammation and anti-inflammatory strategies for Alzheimer's disease. Gerontology 2009; DOI: 10.1159/000237873

[42] Scapagnini G, Caruso C, Vasto S, Pascale A, Romeo L, D' Agata V, et al. Genetic risk factors and candidate biomarkers for Alzheimer's disease. Front Biosci 2010; S2: 616-622.

[43] Britschgi M, Wyss-Coray T. Systemic and acquired immune responses in Alzheimer's disease. Int Rev Neurobiol 2007; 82: 20533.

[44] Di Bona D, Candore G, Franceschi C, Licastro F, Colonna-Romano $\mathrm{G}$, Cammà $\mathrm{C}$, et al. Systematic review by meta-analyses on the possible role of TNF-alpha polymorphisms in association with Alzheimer's disease. Brain Res Rev 2009; 61: 60-8.

[45] Di Bona D, Plaia A, Vasto S, Cavallone L, Lescai F, Franceschi C, et al. Association between the interleukin-1beta polymorphisms and Alzheimer's disease: a systematic review and meta-analysis. Brain Res Rev 2008; 59: 155-63.

[46] Di Bona D, Scapagnini G, Candore G, Castiglia L, ColonnaRomano G, Duro G, et al. Immune-inflammatory responses and oxidative stress in Alzheimer' disease: therapeuthic implications. Curr Pharm Des 2010; 16: 684-691.

[47] Licastro F, Porcellini E, Caruso C, Lio D, Corder EH. Genetic risk profiles for Alzheimer's disease: integration of APOE genotype and variants that up-regulate inflammation. Neurobiol Aging 2007; 28: $1637-43$.

[48] Whitehouse PJ, Price DL, Clark AW, Coyle JT, DeLong MR. Alzheimer's disease: evidence for selective loss of cholinergic neurons in the nucleus basalis. Ann Neurol 1981; 10: 122-6.

[49] Whitehouse PJ, Price DL, Struble RG, Clark AW, Coyle JT, Delon MR. Alzheimer's disease and senile dementia: loss of neurons in the basal forebrain. Science 1982; 215: 1237-9.

[50] Perry EK, Perry RH, Blessed G, Tomlinson BE. Changes in brain cholinesterases in senile dementia of the Alzheimer type. Neuropathol Appl Neurobiol 1978; 4: 273-7.

[51] Ladner CJ, Lee JM. Pharmacological treatment of Alzheimer's disease: the cholinergic hypothesis revisited. J Neuropathol Exp Neurol 1998; 57: 719-31.

[52] Alcaro S, Arcone R, Costa G, De Vita D, Iannone M, Ortuso F, et al. Simple coline esters as potential anti-Alzheimer agents. Curr Pharm Des 2010; 16: 692-697.

[53] Lanni C, Stanga S, Racchi M, Govoni S. The expanding universe of neurotrophic factors: therapeutic potential in aging and ageassociated disorders. Curr Pharm Des 2010; 16: 698-717.
[54] Zampieri N, Chao MV. Mechanisms of neurotrophin receptor signalling. Biochem Soc Trans 2006; 34: 607-11.

[55] Govoni S, Amadio M, Battaini F, Pascale A. Senescence of the brain: focus on cognitive kinases. Curr Pharm Des 2010; 16: 660671.

[56] Campisi J, Yaswen P. Aging and cancer cell biology. Aging Cell 2009; 8: 221-5.

[57] Ries GLA, Reichman ME, Lewis DR, Hankey BF, Edwards BK Cancer survival and incidence from the surveillance, epidemiology, and end results (SEER) program. Oncologist 2003; 8: 541-52.

[58] Finkel T, Serrano M, Blasco MA. The common biology of cancer and ageing. Nature 2007; 448: 767-74

[59] Vasto S, Carruba G, Lio D, Colonna-Romano G, Di Bona D, Candore G, et al. Inflammation, ageing and cancer. Mech Ageing Dev 2009; 130: 40-5

[60] Terry DF, Wilcox MA, McCormick MA, Pennington JY, Schoenhofen EA, Andersen SL, et al. Lower all-cause, cardiovascular, and cancer mortality in centenarians' offspring. J Am Geriatr Soc 2004; 52: 2074-6.

[61] Franceschi C, Motta L, Motta M, Malaguarnera M, Capri M, Vasto $\mathrm{S}$, et al. The extreme longevity: the state of the art in Italy. Exp Gerontol 2008; 43: 45-52.

[62] Caruso C, Balistreri CR, Candore G, Carruba G, Colonna-Romano $\mathrm{G}$, Di Bona D, et al. Polymorphisms of pro-inflammatory genes and prostate cancer risk: a pharmacogenomic approach. Cancer Immunol Immunother 2009; 58: 1919-33.

[63] Derhovanessian E, Solana R, Larbi A, Pawelec G. Immunity, ageing and cancer. Immun Ageing 2008; 5:11.

[64] Finn OJ. Human tumor antigens, immunosurveillance, and cancer vaccines. Immunol Res 2006; 36: 73-82.

[65] Hsu PI, Lai KH, Hsu PN, Lo GH, Yu HC, Chen WC, et al. Helicobacter pylori infection and the risk of gastric malignancy. Am J Gastroenterol 2007; 102: 102725-30.

[66] Zisman TL, Rubin DT. Colorectal cancer and dysplasia in inflammatory bowel disease. World J Gastroenterol 2008; 714: 266-

[67] Vasto S, Carruba G, Candore G, Italiano E, Di Bona D, Caruso C. Inflammation and prostate cancer. Future Oncol 2008; 4: 637-45.

[68] Allavena P, Garlanda C, Borrello MG, Sica A, Mantovani A Pathways connecting inflammation and cancer. Curr Opin Genet Dev 2008; 1: 3-10.

[69] Mantovani A, Allavena P, Sica A, Balkwill F. Cancer related inflammation. Nature 2008; 454: 436-44.

[70] Balistreri CR, Caruso C, Carruba G, Miceli V, Campisi I, Listì F, et al. A pilot study on prostate cancer risk and pro-inflammatory genotypes: pathophysiology and therapeutic implications. Curr Pharm Des 2010; 16: 718-724.

[71] Lucenteforte E, Talamini R, Montella M, Dal Maso L, Tavani A, Deandrea S, et al. Macronutrients, fatty acids and cholesterol intake and endometrial cancer. Ann Oncol 2008; 19: 168-72.

[72] Bahmanyar S, Ye W. Dietary patterns and risk of squamous-cell carcinoma and adenocarcinoma of the esophagus and adenocarcinoma of the gastric cardia: a population-based casecontrol study in Sweden. Nutr Cancer 2006; 54: 171-8.

[73] Biasi F, Mascia C, Poli G. The contribution of animal fat oxidation products to colon carcinogenesis, through modulation of TGF-beta1 signaling. Carcinogenesis 2008; 2: 890-4.

[74] Leitzmann MF, Stampfer MJ, Michaud DS, Augustsson K, Colditz GC, Willett WC, et al. Dietary intake of n-3 and n-6 fatty acids and the risk of prostate cancer. Am J Clin Nutr 2004; 80: 204-16.

[75] Schmitz G, Ecker J. The opposing effects of n-3 and n-6 fatty acids. Prog Lipid Res 2008; 47: 147-55.

[76] Taha AS, Hudson N, Hawkey CJ, Swannell AJ, Trye PN, Cottrell J, et al. Famotidine for the prevention of gastric and duodenal ulcers caused by nonsteroidal antiinflammatory drugs. N Engl J Med 1996; 334: 1435-9.

[77] Sporn MB, Liby KT. Cancer chemoprevention: scientific promise, clinical uncertainty. Nat Clin Pract Oncol 2005; 2: 51825.

[78] Mann JR, Backlund MG, DuBois RN. Mechanisms of disease: Inflammatory mediators and cancer prevention. Nat Clin Pract Oncol 2005; 2: 202-10.

[79] Menna C, Olivieri F, Catalano A, Procopio A. Lipoxygenase inhibitors for cancer prevention: promises and risks. Curr Pharm Des 2010; 16: 725-733. 
[80] Petta S, Craxì A. Hepatocellular carcinoma and non-alcoholic fatty liver disease: from a clinical to a molecular association. Curr Pharm Des 2010; 16: 741-752.

[81] Otto SP, Whitton J. Polyploid incidence and evolution. Annu Rev Genet 2000; 34: 401-37.

[82] Yang D, McCrann DJ, Nguyen H, St Hilaire C, DePinho RA, Jones $\mathrm{MR}$, et al. Increased polyploidy in aortic vascular smooth muscle cells during aging is marked by cellular senescence. Aging Cell 2007; 6: 257-60.

[83] Storchova Z, Kuffer C. The consequences of tetraploidy and aneuploidy. J Cell Sci 2008; 121: 3859-66.

[84] Narita M, Lowe SW. Senescence comes of age. Nat Med 2005; 11: 920-2.

[85] Mason DX, Jackson TJ, Lin AW. Molecular signature of oncogenic ras-induced senescence. Oncogene 2004; 23: 9238-46.

[86] Mosieniak G, Sikora E. Poliploidy: the link between senescence and cancer. Curr Pharm Des 2010; 16: 734-740.

[87] Ridker PM. On evolutionary biology, inflammation, infection, and the causes of atherosclerosis. Circulation 2002; 105: 2-4.

[88] Fernandez-Real JM, Ricart W. Insulin resistance and inflammation in an evolutionary perspective: the contribution of cytokine genotype/phenotype to thriftiness. Diabetologia 1999; 42: 1367-74.

[89] Packard RR, Lichtman AH, Libby P. Innate and adaptive immunity in atherosclerosis. Semin Immunopathol 2009; 31: 5-22.

[90] Granic I, Dolga AM, Nijholt IM, van Dijk G, Eisel UL. Inflammation and NF-kappaB in Alzheimer's disease and diabetes. J Alzheimers Dis 2009; 16: 809-21.

[91] Murray CJ, Lopez AD. Global mortality, disability, and the contribution of risk factors: Global burden of disease study. Lancet 1997; 349: 1436-42.

[92] Chung HY, Cesari M, Anton S, Marzetti E, Giovannini S, Seo AY, et al. Molecular inflammation: underpinnings of aging and agerelated diseases. Ageing Res Rev 2009; 8: 18-30.

[93] Listì F, Caruso M, Incalcaterra E, Hoffmann E, Caimi G, Balistreri $\mathrm{CR}$, et al. Pro-inflammatory gene variants in myocardial infarction and longevity: implications for pharmacogenomics. Curr Pharm Des 2008; 14: 2678-85.

[94] Candore G, Balistreri CR, Caruso M, Grimaldi MP, Incalcaterra E, Listì F, et al. Pharmacogenomics: a tool to prevent and cure coronary heart disease. Curr Pharm Des 2007; 13: 3726-34.

[95] Grimaldi MP, Vasto S, Balistreri CR, Di Carlo D, Caruso M, Incalcaterra E, et al. Genetics of inflammation in age-related atherosclerosis: its relevance to pharmacogenomics. Ann N Y Acad Sci 2007; 1100: 123-31.

[96] Licastro F, Chiappelli M, Porcellini E, Campo G, Buscema M, Grossi E, et al. Gene-gene and gene-clinical factors interaction in acute myocardial infarction: a new detailed risk chart. Curr Pharm Des 2010; 16: 783-788.

[97] Bennati E, Murphy A, Cambien F, Whitehead AS, Archbold GPR, Young IS, et al. Belfast centenarians: a case of optimized cardiovascular risk? Curr Pharm Des 2010; 16: 789-795.

[98] Nicita-Mauro V, Maltese G, Nicita-Mauro C, Lasco A, Basile G. Non smoking for successful aging: therapeutic perspectives. Curr Pharm Des 2010; 16: 775-782.

[99] Nicita-Mauro V, Basile G, Maltese G, Nicita-Mauro C, Gangemi S, Caruso C. Smoking, health and ageing. Immun Ageing 2008; 5: 10.

[100] Hardoon SL, Whincup PH, Lennon LT, Wannamethee SG, Capewell S, Morris RW. How much of the recent decline in the incidence of myocardial infarction in British men can be explained by changes in cardiovascular risk factors?: Evidence from a prospective population-based study. Circulation 2008; 117: 5 98604.

[101] Jensen MK, Chiuve SE, Rimm EB, Dethlefsen C, Tjønneland A, Joensen AM, et al. Obesity, behavioral lifestyle factors, and risk of acute coronary events. Circulation 2008; 117: 3062-9.

[102] Panaro MA, Acquafredda A, Cavallo P, Cianciulli A, Saponaro C, Mitolo V. Inflammatory responses in embryonal cardiomyocytes exposed to LPS challenge. An in vitro model of deciphering the effects of LPS on the heart. Curr Pharm Des 2010; 16: 754-765.

[103] Panaro MA, Gagliardi N, Saponaro C, Calvello R, Mitolo V, Cianciulli A. Toll-like receptor 4 mediates LPS-induced release of nitric oxide and tumor necrosis factor-alpha by embryonal cardiomyocytes: biological significance and clinical implications in human pathology. Curr Pharm Des 2010; 16: 766-774.

[104] Forte GI, Pilato G, Vaccarino L, Sanacore M, Candore G, Colonna Romano $\mathrm{G}$, et al. Risk of profiles in type 2 diabetes (Metabolic
Syndrome): integration of IL-10 polymorphisms and laboratory parameters to identify vascular damages related complications. Curr Pharm Des 2010; 16: 898-903.

[105] Franceschi C, Capri M, Monti D, Giunta S, Olivieri F, Sevini F, et al. Inflammaging and antiinflammaging: a systemic perspective on aging and longevity emerged from studies in humans. Mech Ageing Dev 2007; 128: 92-105.

[106] Caruso C, Candore G, Colonna-Romano G, Lio D, Franceschi C. Inflammation and life-span. Science 2005; 307: 208-9.

[107] Franceschi C, Bonafe M. Centenarians as a model for healthy aging. Biochem Soc Trans 2003; 31: 457-61.

[108] Di Bona D, Vasto S, Capurso C, Christiansen L, Deiana L, Franceschi C, et al. Effect of interleukin-6 polymorphisms on human longevity: a systematic review and meta-analysis. Ageing Res Rev 2009; 8: 36-42.

[109] Singh R, Kølvraa S, Bross P, Christensen K, Bathum L, Gregersen $\mathrm{N}$, et al. Anti-inflammatory heat shock protein 70 genes are positively associated with human survival. Curr Pharm Des 2010; 16: 796-801.

[110] Hooper PL, Hooper PL. Inflammation, heat shock proteins, and type 2 diabetes. Cell Stress Chaperones 2009; 14: 113-5.

[111] Njemini R, Demanet C, Mets T. Inflammatory status as an important determinant of heat shock protein 70 serum concentrations during aging. Biogerontology 2004; 5: 31-8.

[112] Njemini R, Bautmans I, Lambert M, Demanet C, Mets T. Heat shock proteins and chemokine/cytokine secretion profile in ageing and inflammation. Mech Ageing Dev 2007; 128: 450-4.

[113] Salvioli S, Olivieri F, Marchegiani F, Cardelli M, Santoro A, Bellavista $\mathrm{E}$, et al. Genes, ageing and longevity in humans: problems, advantages and perspectives. Free Radic Res 2006; 40: 1303-23.

[114] De Benedictis G, Franceschi C. The unusual genetics of human longevity. Sci Aging Knowl Environ 2006; 10: pe20.

[115] Fraga MF, Ballestar E, Paz MF, Roper S, Setien F, Ballestar ML, et al. Epigenetic differences arise during the lifetime of monozygotic twins. Proc Natl Acad Sci USA 2005; 102: 10604-9.

[116] Elbaz A, Dufouil C, Alpérovitch A. Interaction between genes and environment in neurodegenerative diseases. C R Biol 2007; 330: 318-28.

[117] Cevenini E, Bellavista E, Tieri P, Castellani G, Lescai F, Francesconi M, et al. Systems biology and longevity: an emerging approach to identify innovative anti-aging targets and strategies. Curr Pharm Des 2010; 16: 802-813.

[118] Marian M, Sacks G. Micronutrients and older adults. Nutr Clin Pract 2009; 24: 179-95.

[119] Abate M, Di Iorio A, Di Renzo D, Paganelli R, Saggini R, Abate G Frailty in the elderly: the physical dimension. Eura Medicophys 2007; 43: 407-15.

[120] Topinková E. Aging, disability and frailty. Ann Nutr Metab 2008; 52: 6-11.

[121] Joseph JA, Shukitt-Hale B, Willis LM. Grape juice, berries, and walnuts affect brain aging and behavior. J Nutr 2009; 139: 1813S$7 \mathrm{~S}$.

[122] Hoyles L, Vulevic J. Diet, immunity and functional foods. Adv Exp Med Biol 2008; 635: 79-92.

[123] Salminen S, Bouley C, Boutron-Ruault MC, Cummings J, Franck $\mathrm{A}$, at al. Functional food science and gastrointestinal physiology and function. Br J Nutr 1998; 80: S147-S171.

[124] Sanders ME. Probiotics. Food Technol 1999; 53: 67-77.

[125] Linsalata M, Cavallini A, Messa C, Orlando A, Refolo MG, Russo F. Lactobacillus rhamnosus GG influences polyamine metabolism in HGC-27 gastric cancer cell line: strategy toward nutritional approach to chemoprevention of gastric cancer. Curr Pharm Des 2010; 16: 847-853

[126] Jirillo F, Jirillo E, Magrone T. Donkey's and goat's milk consumption and benefits to human health with special reference to the inflammatory status. Curr Pharm Des 2010; 16: 859-863.

[127] Wu G. Amino acids: metabolism, functions, and nutrition Amino Acids 2009; 37: 1-17.

[128] Sikora E, Bielak-Żmijewska A, Mosieniak G, Piwocka K. The promise of slow down ageing may come from curcumin. Curr Pharm Des 2010; 16: 884-892.

[129] Amati L, Marzulli G, Martulli M, Chiloiro M, Jirillo E. Effect of a hypocaloric diet on obesity biomarkers: prevention of low grade inflammation since childhood. Curr Pharm Des 2010; 16: 893-897. 
[130] Amati L, Marzulli G, Martulli M, Pugliese V, Caruso C, Candore $\mathrm{G}$, et al. Administration of a synbiotic to free-living elderly and evaluation of serum cytokines. A pilot study. Curr Pharm Des 2010; 16: 854-858.

[131] De Lorenzo A, Noce A, Bigioni M, Calabrese V, Della Rocca DG, Daniele N, et al. The effects of Italian Mediterranean Organic Diet (IMOD) on health status. Curr Pharm Des 2010; 16: 814-824.

[132] Carbonelli MG, Di Renzo L, Bigioni M, Di Daniele N, De Lorenzo A, Fusco MA. $\alpha$-Lipoic acid supplementation: a tool for obesity therapy? Curr Pharm Des 2010; 16: 840-846.

[133] Russo F, Riezzo G, Chiloiro M, De Michele G, Chimienti G, Marconi E, et al. Metabolic effect of a diet with inulin-enriched pasta in healthy young volunteers. Curr Pharm Des 2010; 16: 825831.

[134] Jirillo F, Martemucci G, D’Alessandro AG, Panaro MA, Cianciulli A, et al. Ability of goat milk to modulate healthy human peripheral blood lymphomonocyte and polymorphonuclear cell function: in vitro effects and clinical implications. Curr Pharm Des 2010; 16: 870-876.

[135] Amati L, Marzulli G, Martulli M, Tafaro A, Jirillo F, Puglise V, et al. Donkey and goat milk intake and modulation of the human aged immune response. Curr Pharm Des 2010; 16: 864-869.

[136] Barbagallo M, Dominguez LJ. Magnesium and aging. Curr Pharm Des 2010; 16: 832-839.

[137] Meydani M. Antioxidants and cognitive function. Nutr Rev 2001; 59: S75-S80.

[138] Calabrese V, Cornelius C, Trovato A, Cavallaro M, Mancuso C, Di Rienzo L, et al. The Hormetic role of dietary antioxidant in free radical-related diseases. Curr Pharm Des 2010; 16: 877-883.
[139] Valko M, Rhodes CJ, Moncol J, IzakovicM, Mazur M. Free radicals, metals and antioxidants in oxidative stress-induced cancer. Chem Biol Interact 2006; 160: 1-40.

[140] Cortese-Krott MM, Suschek CV, Wetzel W, Kröncke KD, KolbBachofen V. Nitric oxide-mediated protection of endothelial cells from hydrogen peroxide is mediated by intracellular zinc and glutathione. Am J Physiol Cell Physiol 2009; 296: C811-20.

[141] Packer L, Witt E, Tritschler H. Alpha-lipoic as a biological antioxidant. Free Radic Biol Med 1995; 19: 227-50.

[142] Oeppen J, Vaupel JW. Demography. Broken limits to life expectancy. Science 2002; 296: 1029-31.

[143] Olshansky SJ, Ault AB. The fourth stage of the epidemiologic transition: the age of delayed degenerative diseases. Milbank Q 1986; 64: 355-91.

[144] Butler RN, Miller RA, Perry D, Carnes BA, Williams TF, Cassel C, et al. New model of health promotion and disease prevention for the 21 st century. BMJ 2008; 337: 149-50.

[145] Hekimi S. How genetic analysis tests theories of animal aging. Nat Genet 2006; 38: 985-91.

[146] Farrelly C. Has the time come to take on time itself? BMJ 2008; 337: 147-8.

[147] Olshansky SJ, Perry D, Miller RA, Butler RN. Pursuing the longevity dividend: scientific goals for an aging world. Ann N Y Acad Sci 2007; 1114: 11-3.

[148] Jirillo E, Candore G, Magrone T, Caruso C. A scientific approach to anti-ageing therapies: state of the art. Curr Pharm Des 2008; 14: 2637-42. 